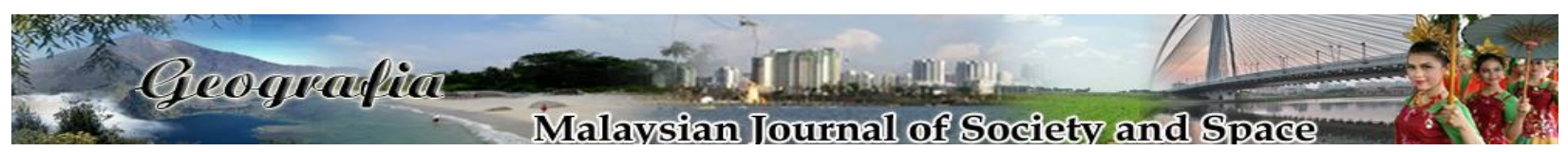

\title{
Pemberimilikan tanah: Sebab pendorong kepada pertikaian dalam pembangunan tanah
}

\author{
Azima A.M, Mohd Shafiq Akmal Kasimon \\ Program Sains Pembangunan, Fakulti Sains Sosial dan Kemanusiaan, Universiti Kebangsaan Malaysia \\ Correspondence: Azima A.M (azima@ukm.edu.my)
}

Received: 09 February 2021; Accepted: 12 June 2021; Published: 27 August 2021

\begin{abstract}
Abstrak
Pemberimilikan tanah melalui beberapa kaedah penganugerahan pemilikan telah mencetuskan pertikaian pemilikan khusus dalam pembangunan tanah di beberapa daerah di negeri Sabah. Perasaan tidak puas hati pemilik tanah ini telah mencetuskan konflik dalam kalangan mereka dengan pihak agensi yang terlibat. Pelbagai penentangan terhadap usaha penganugerahan pemilikan tanah yang dijalankan didapati boleh menyebabkan usaha pembangunan tanah kawasan setempat akan terganggu. Keadaan ini disebabkan oleh kebimbangan masyarakat setempat terhadap keberadaan tanah natif masyarakat adat. Perasaan takut dan bimbang ini boleh mewujudkan halangan terhadap pembangunan tanah apabila ramai dalam kalangan pemilik tanah mula mempertikaian keperluan terhadap kaedah pemilikan yang ingin dijalankan oleh pihak agensi yang berkaitan. Sehubungan itu, adalah menjadi satu keperluan penelitian terhadap punca atau sebab yang mendorong kepada pertikaian yang berlaku antara pemilik tanah dengan pihak agensi yang berkaitan. Oleh itu, artikel ini bertujuan untuk merungkai punca yang menyebabkan bantahan pemilik tanah terhadap beberapa kaedah pemberimilikan tanah yang telah dilaksanakan dalam pembangunan tanah. Bagi membolehkan pengkaji memahami punca yang mendorong kepada berlakunya pertikaian dalam kalangan pemilik tanah, maka pendekatan institusi ekonomi telah digunapakai untuk merungkai sebab yang menyebabkan bantahan pemilik tanah. Temubual mendalam telah dilakukan dengan pemilik tanah di kawasan kajian. Tujuannya adalah untuk mendapatkan pandangan mereka berhubung dengan sebab yang mendorong kepada pertikaian pemberimilikan tanah melalui kaedah geran komunal. Beberapa soalan terpandu telah digunakan bagi mendapatkan sebab mereka membantah penganugerahan milikan tanah secara geran komunal. Dapatan kajian menjelaskan bahawa terdapat beberapa faktor yang mendorong pertikaian masyarakat setempat antaranya Akta Tanah Adat (NCR), peruntukan Geran Komunal dan sistem pengagihan tanah. Manakala bagi faktor informal pula merangkumi ketelusan pihak berkuasa, adat dan budaya yang menjadi penyebab kepada pertikaian pemilikan tanah NCR. Rumusannya antara sebab yang membawa kepada pertikaian tanah NCR adalah berkait dengan kebimbangan, kerisauan dan keraguan mereka terhadap keberadaan tanah tanah untuk generasi seterusnya.
\end{abstract}


Kata kunci: Bantahan, pertikaian, penganugerahan pemilikan, pendekatan institusi, pembangunan tanah

\title{
Land alienation: Causes that lead to dispute on land development
}

\begin{abstract}
Land alienation through several ownership award method has triggered ownership disputes on land development in several districts in Sabah. The dissatisfaction of the landowners has triggered conflict in their circles with the agencies involved. Various resistance to the land alienation efforts undertaken were found to be disruptive to the land development efforts of the local area. This is due to the concern of the local community over the existence of the native land of the customary community. These fears and worry could create barriers to land development when many of the landowners began to dispute the need for the ownership method to be carried out by the relevant agencies in the land development. In this regard, it is a need for scrutiny of the reasons or causes leading to the disputes between the landowners and the relevant agencies. Therefore, the purpose of this article is to shed light on the underlying causes of the objection by landowners against several land alienation methods that have been implemented. To enable the researchers to understand the underlying causes of the disputes among the landowners, the economic institution's approach has been used to address the underlying causes for the objection of landowners. Thus, an in-depth interview with the native landowners in the Semporna district of Sabah has been conducted. The purpose is to obtain their views in relation to the causes that lead to the dispute of land alienation through the Communal Grant method. A few guided questions were used to obtain the reason for them to object to the land ownership by communal grants. The findings of the study explained that there were several factors that led to the local community disputes including the Customary Land Act (NCR), the provision of Communal Grants and land distribution systems. The informal factors include transparency of the authority, customs and culture which are the causes of the dispute of the NCR land ownership. The reason for the NCR land dispute is related to their concerns and doubts about the availability of the land for the next generation.
\end{abstract}

Keywords: Objections, disputes, ownership award, institutional approach, land development

\section{Pengenalan}

Pertikaian pemilikan tanah berlaku apabila adanya perubahan yang berlaku dalam sesebuah komuniti. Perubahan yang dimaksudkan melibatkan usaha membangunkan sesebuah dengan kawasan penempatan dan sebagainya. Situasi ini mula mengundang konflik apabila masyarakat adat mendapati tanah yang pernah menjadi sebahagian daripada kehidupan mereka telah diganggu atas nama pembangunan. Keadaan menjadi semakin terhempit apabila hak masyarakat adat terhadap tanah dinafikan secara eklusif dan insentifnya (Hasan Mat Noor, 2002; Ganta, 2019). Hal ini sangat berkait dengan dengan kuasa autoriti yang dimiliki oleh kerajaan negeri dan juga oleh pemodal terhadap tanah. Dalam hal ini kerajaan negeri memberikan perhatian terhadap kawasan yang boleh didiami oleh masyarakat adat.Rasa tidak puas hati masyarakat adat ini telah 
menimbulkan pertikaian antara kedua-dua belah pihak yang jelasnya mempunyai kepentingan tertentu terhadap tanah.

Wehrmann (2008) mendefinisikan pertikaian tanah sebagai satu fakta sosial yang melibatkan sekurang-kurangnya dua pihak berpunca daripada perbezaan kepentingan ke atas tanah sama ada berpaksikan keperluan atau ketamakan pihak yang terlibat. Perkara ini disokong oleh Shahidul et al. (2015) yang menyatakan puncanya adalah daripada makna yang tersendiri terhadap pemilikan tanah. Oleh itu, untuk mengkaji kes-kes pertikaian tanah, landasan pertama yang perlu diketahui adalah tujuan dan kepentingan tanah tersebut kepada pihak-pihak yang terlibat. Wehrmann (2008) menggariskan kedudukan psikologi iaitu ketakutan dan keinginan akan menentukan keperluan emosi dan material lantas mencorakkan minat yang dipengaruhi oleh sikap dan kuasa. Perkara ini akan melahirkan tindak tanduk tertentu yang mencetuskan konflik. Dengan mengetahui kepentingan sesebuah tanah, pengkaji dapat mencari akar kepada timbulnya konflik sama ada disebabkan kebimbangan atau keinginan terhadap tanah oleh pihak yang terlibat.

Kajian Hebo (2005) di Ethiopia mendapati pertikaian tanah lazimnya berpunca daripada beberapa faktor iaitu hak adat bertentangan dengan hak politik, pertikaian hak politik, pewarisan, jual-beli, pemajakan tanah dan sempadan tanah kaum. Dalam konteks yang dikaji oleh Hebo (2005), hak adat adalah hak ke atas tanah yang diperoleh melalui pewarisan harta patriarki (bersifat lokal) berbanding hak politik yang diperoleh daripada kerangka yang disediakan oleh pihak berkuasa. Pengkaji mendapati punca utama adalah pertikaian hak adat lazimnya tidak ada perjanjian hitam putih dan ianya seringkali bertentangan dengan hak politik jelas dalam undangundang dan akta yang sedia ada.

United Nations (2012) membincangkan konteks pertikaian tanah apabila pertikaian tersebut menjadi konflik ganas ("violent conflict"). Pendapat organisasi ini adalah pertikaian tanah bersifat dinamik dan kemunculannya berhubungan besar dengan sumber di sekitarnya. Organisasi ini memperkenalkan kitaran konflik yang mempunyai lima tahap yang penting, ketidakpuasan hati, rasa tidak selamat, konflik, rundingan \& perdamaian, dan pasca-konflik. Kitaran bermula dengan ketidakpuasan terjadi apabila berlaku isu atau tuntutan ke atas tanah daripada satu pihak kepada pihak lain. Selepas timbul ketidakpuasan hati, ini akan menyebabkan sesuatu pihak itu berasa tergugat dan tidak selamat iaitu tahap kedua. Tahap ketiga adalah pencetusan konflik iaitu perubahan daripada bentuk perasaan yang negatif tersebut menjadi perbuatan, konflik ganas. Tahap tiga juga melibat kepada evolusi konflik tersebut merentasi masa. Tahap keempat merujuk kepada usaha penyelesaian masalah melalui rundingan dan. Terakhir sekali, pasca-konflik (tahap kelima) adalah konflik yang telah selesai dan pertolongan dapat berjalan lancar.

Pertikaian tanah dapat diberikan kepada dua keadaan iaitu biasa dan konflik (IOM dan World Bank, 2013). Keadaan rendah merujuk kepada kes-kes tanpa penglibatan politik seperti pewarisan harta dan pertikaian sempadan berskala kecil antara jiran tetangga. Konflik melibatkan faktor politik dan keterlibatan komuniti yang lebih luas. Pada keadaan ini, konflik dapat diselesaikan dengan polisi dan undang-undang kerana masalah itu sendiri berada pada luar lingkaran undang-undang sedia ada. Dalam konteks tanah masyarakat adat, didapati undangundang pemilikan tanah yang diperoleh mereka tidak cenderung menjaga kebajikan mereka dalam konteks pemilikan ((Marcus et al., 2011). Keadaan ini mengundang pertikaian dan seterusnya menganggu proses pembangunan tanah oleh kerajaan negeri. Justeru pemberimilikan tanah secara geran komunal di Sabah akan dibincangkan dalam konteks. Tujuan asal pemberian hakmilik tanah melalui kaedah komunal ini bertujuan untuk menangani isu pemilikan tanah native di Sabah. Namun usaha yang dijalankan oleh kerajaan negeri ini telah menimbul pertikaian dalam kalangan pemilik tanah adat. Bagi menjawab persoalan yang menyebabkan wujudnya pertikaian antara 
pemilik tanah dan kerajaan negeri ini. Maka pendekatan institusi telah digunakan untuk merungkai sebab yang mendorong pertikaian yang berlaku.

\section{Metodologi}

Kajian ini merupakan kajian kualitatif melalui kaedah temubual mendalam dengan pemilik tanah adat yang terlibat. Pemilik tanah dalam kajian ini merupakan mereka yang terlibat dengan proses penganugerahan pemilikan tanah melalui kaedah geran komunal. Pendekatan institusi telah digunakan sebagai kerangka bagi membolehkan pemilik tanah memberikan pandangan berhubung dengan sebab mereka membantah penganugerahan pemilikan tanah melalui kaedah geran komunal. Pendekatan institusi telah membahagikan sebab bantahan penduduk kepada dua iaitu punca formal dan informal. Hal ini perlu diselidiki bagi mendapatkan punca yang membawa kepada pertikaian mereka terhadap usaha pihak agensi terlibat. Semakan silang daripada pemilik tanah telah dibuat dengan ketua yang juga dikenali sebagai 'Panglima' bagi masyarakat adat didaerah ini telah dilakukan. Selain itu, semakan silang juga dibuat dengan pegawai daripada Pejabat Tanah dan Daerah Semporna, Sabah.

\section{Pendekatan institusi}

Institusi merupakan sebuah sistem yang mencorakkan dan dicorakkan oleh peraturan-peraturan sosial (Hodgson, 2006) dan seterusnya melahirkan fakta institusi yang difahami oleh ahli-ahlinya sahaja (Searle, 2005). Azima \& Er (2015) dan Searle (2005) bersetuju bahawa ekonomi manusia dipengaruhi oleh sistem institusi. Hal ini dapat diperhatikan apabila wujudnya perbezaan amalan antara satu tempat dengan satu tempat yang lain, sebagai contoh amalan pewarisan tanah. Dalam konteks pewarisan tanah, Malaysia misalnya mempraktikkan sistem sivil dan syariah manakala Thailand pula mengamalkan amalan pewarisan tanah di bawah kod sivil. Keadaan ini bersesuaian dalam konteks amalan dan budaya yang diamalkan oleh masyarakat masing-masing. Perbezaan dalam struktur budaya ini sudah pasti mampu mengundang konflik dalaman antara pihak agensi dengan komuniti setempat. Konflik yang berpanjangan ini sudah pasti mengundang pertikaian dan seterusnya memberi implikasi terhadap proses pembangunan tanah.

Keadaan ini menjelaskan tentang perihal implikasi perubahan dalam institusi yang secara implisitnya menekankan institusi dalam konteks formal dan informal (Mair \& Miller, 1992, North, 1996, Azima, 2013). Oleh yang demikian suatu pendekatan yang holistik dalam proses pembangunan tanah diperlukan agar kedua-dua aspek ormal dan informal ini dapat diteliti. Tujuan agar kedinamikan dalam aspek sosial, ekonomi dan politik boleh dirungkai dengan lebih berkesan (Azima et al., 2012; Hazakis, 2014). Ini kerana institusi juga dirujuk sebagai perubahan dan kedinamikan yang berkait langsung dengan peraturan formal serta peraturan informal seperti budaya yang melibatkan hubungan serta integrasi dalam masyarakat.

Sehubungan itu, dapat dijelaskan bahawa institusi memainkan peranan yang penting dalam mempengaruhi kedinamikan proses perubahan institusi. Pendekatan institusi percaya bahawa pendekatan ini merupakan antara pendekatan yang dapat memainkan peranan dalam penentuan dan pembahagian sumber yang ada (Mair \& Miller, 1992). Kewujudan struktur kuasa dan interaksi ejen dengan pelbagai peraturan formal dan informal, mewujudkan keseimbangan dalam pembangunan tanah. Ini kerana sifat pasaran harta tanah pertanian yang dinamik dan keputusan ejen yang kolektif boleh memacu perubahan institusi pasaran berkenaan. Jadi, 
pendekatan institusi boleh menentukan perubahan institusi yang terkait dengan pola perubahan yang berlaku dalam penawaran dan permintaan dalam proses pembangunan.

Oleh yang demikian dapat dirumuskan bahawa pendekatan ini menhujahkan bahawa struktur institusi terbentuk apabila wujudnya perubahan dalam sistem perundangan yang akhirnya memberi implikasi terhadap pembentukan institusi (Mair \& Miller, 1992). Maka dalam konteks proses pembangunan tanah, kerangka konsepsual yang rasional dan dinamik dapat dijadikan asas dalam meneliti halangan mahupun punca mendorong berlakunya pertikaian dalam proses pembangunan tanah masyarakat setempat seperti tanah adat.

\section{Isu pertikaian tanah}

Pertikaian dalam pemilikan tanah adat di daerah Semporna Sabah banyak berkait dengan cara pemberimilikan tanah oleh kerajaan negeri dan pemilik tanah. Pertikaian dalam pemilikan didaerah ini kebanyakkannya melibatkan tuntutan terhadap tanah adat. Tuntutan terhadap pemilik tanah adat pada asasnya melibatkan tuntutan pemilikan oleh generasi kedua. Tuntutan yang berulang kali terhadap tanah yang sedia ada menyebabkan timbulnya isu pertindihan permohonan tanah oleh pemilik tanah. Dapatan daripada analisis mendapati wujud dua isu yang membawa kepada pertikaian dalam pemilikan tanah di daerah ini antaranya ialah isu orang asal tidak tahu mereka mempunyai hak terhadap tanah dan hak tanah diberikan hak milik kepada pihak luar.

\section{Orang Asal tidak tahu mereka mempunyai hak}

Pertikaian ini kebanyakannya berpunca daripada kurang pengetahuan orang asal terhadap hak tanah adat. Ramai dalam kalangan pemilik tanah adat kurang sedar wujudnya peruntukan tanah adat dan seksyen-seksyen tertentu di dalam tanah adat. Majoriti pemilik tanah menjelaskan bahawa mereka tidak pernah mendengar dan diberitahu oleh sesiapa berhubung dengan hak tanah adat seperti yang tercatat dalam seksyen 1, 14,15, 16 dan 17 Bahagian IV Ordinan Tanah Sabah Bab 68. Keadaan ini jelas mengambarkan betapa naifnya mereka terhadap undang-undang tanah yang mereka miliki. Pemilik yang tidak mempunyai pengetahuan tentang ordinan ini dengan mudahnya dipermainkan oleh mereka yang mempunyai kepentingan tertentu terhadap tanah. Hal ini jelas apabila ramai dalam kalangan pemilik tanah yang beranggapan bahawa tanah kelahiran nenekmoyang mereka adalah secara semula jadi dan seterusnya menjadi hak milik mereka berdasarkan kepada adat dan budaya mereka (Ah Choy Er et al., 2021; Lee Jing, 2017). Hal ini menyebabkan masyarakat adat tidak membuat sebarang tindakan untuk mengesahkan pemilikan tanah adat mereka dengan lebih awal (Suruhanjaya Hak Asasi Manusia).

Hal ini jelas apabila masyarakat adat menjelaskan bahawa "tanah nenak moyang saya secara automatik akan menjadi sebahagian hak saya berdasarkan adat. Keadaan ini menjelaskan bahawa pengetahuan mereka tentang tanah sememang dipengaruhi oleh maklumat lisan yang diperoleh daripada nenek moyang mereka. Bagi mereka, adat dan budaya yang dianuti dan dimiliki merupakan sandaran kepada perolehan mereka terhadap sumber tanah. Hanya dengan maklumat lisan yang diperoleh daripada ketua keluarga dan ketua sahaja yang digunakan oleh mereka untuk mempertahankan hak mereka terhadap tanah. Hal ini jelas melalui temubual dengan salah pemilik tanah yang menyatakan bahawa; 
“...tanah milik moyang saya..dan ia akan diwarisi oleh anak-anak dan cucu saya...takde yang boleh merampas hak kami..."

Dapatan ini menjelaskan bahawa jika tanah mereka diambil atau diberikan kepada pihak ketiga mereka perlu diberitahu dan perbincangan perlu mengambilkira semua ahli masyarakat yang terlibat dalam suku kaum mereka. Namun seringkali berlaku mereka tidak dibawa dirunding malah tidak diberitahu mengenai pengambilan tanah mereka. Ini kerana maklumat yang ada di Pejabat Tanah mendapati bahawa tanah milik suku kaum ini telah termasuk dalam rezab hutan simpan. Hal ini sudah pasti menimbulkan pertikaian diantara kedua-dua pihak.

Pertikaian pemilikan terhadap tanah adat ini juga boleh tercetus apabila sebahagian besar daripada mereka beranggapan bahawa mereka tidak perlu mengesahkan pemilikan mereka secara formal di Pejabat Tanah. Hal ini apabila pandangan mereka terhadap iaitu "tanah nenek moyang saya secara semulajadi adalah hak saya milik saya, jadi saya tidak perlu mengesahkan pemilikannya. Keadaan ini menjelaskan bahawa mereka sangat berpegang kuat pada adat dan budaya yang mereka pegang. Melalui adat yang dipegang pengesahan tanah secara bergeran tidak pernah ditekankan oleh nenek moyang mereka. Ini kerana mereka merupakan orang pertama yang membuka hutan tersebut bagi tujuan penempatan sejak berpuluh tahun. Oleh itu bagi mereka selagi adat hidup maka selagi itu jugalah pemilikan mereka terhadap tanah akan kekal buat selamanya. Bagi mereka walaupun ada peruntukan baru yang diperkenalkan dalm aspek pemberimilik tanah tetapi jika tidak bertepatan dengan undang-undang adat yang mereka pegang maka tanah tersebut perlu dipertahankan. Oleh yang demikian apabila pihak kerajaan memperkenalkan pemberian milikan tanah secara geran komunal, maka ramai dalam kalangan mereka yang menentang. Ini kerana majoriti pemilik tanah adat berpendapat kaedah ini telah tidak mematuhi peruntukan adat yang mereka pegang sejak sekian lama. Situasi ini akhirnya mencetuskan pertikaian hakmilik tanah dalam kalangan pemilik dengan kerajaan negeri.

\section{Hak Tanah Adat Negeri diberikan hak milik kepada pihak luar}

Pertikaian pemilik tanah dengan kerajaan negeri berlaku apabila hak tanah mereka diberikan kepada orang luar bagi tujuan pembukaan ladang dan sebagainya. Dalam hal ini wujud beberapa situasi yang membawa kepada pertikaian pemilikan tanah. Antaranya pihak kerajaan sama ada tanpa usul periksa mahupun secara sengaja, memberikan kelulusan geran kepada orang luar sedangkan kawasan tersebut adalah kawasan Tanah Adat Anak Negeri (NCR) yang telah dihuni dan diusahakan serta telah diwarisi sejak zaman nenek-moyang iaitu sebelum pembentukan negara Malaysia lagi. Hal ini sudah pasti menimbulkan kemarahan kerana pemilik tanah mendakwa mereka amat faham dan arif tentang undang-undang tanah adat. Kebanyakannya mendakwa sangat memahami susur galur pemilikan dan persempadanan tanah yang mereka peroleh sejak zaman Jepun. Hal ini sudah pasti menimbulkan pertikaian apabila sempadan tanah mereka diganggu oleh pihak luar seperti pengusaha ladang.

Dapatan daripada temubual daripada pemilik tanah adat menjelaskan rasa tidak pasti terhadap pengusaha yang mengusahakan tanah yang dulunya didakwa milik mereka;

“...kami tidak puashati kenapa tanah kami diduduki oleh orang luar (syarikat) untuk tanaman kelapa sawit..."

"...tanah tu moyang kami punya...tapi kini ada syarikat sudah tanam kelapa sawit.." 
Pemilik tanah bersetuju bahawa mereka amat jelas dengan peruntukan yang ada dan tidak memerlukan prosedur pengendalian tanah melalui geran oleh pihak kerajaan. Ada dalam kalangan pemilik tanah yang berpendapat bahawa;

"...tanah ini telah lama kami usahakan...dan kami tahu bagaimana mau mengendalikan tanah kami .."

Seterusnya pertikaian tanah adat juga berkait rapat dengan penggunaan surat kuasa. Penggunaan surat kuasa ini juga menyebabkan pemilik tanah adat kehilangan tanah mereka. Kebanyakan kes yang merujuk kepada surat kuasa ini berkait dengan kewujudan orang tengah yang bertindak memujuk pemilik tanah menandatangai persetujuan dengan beberapa insentif.. Rungutan dalam kalangan pemilik tanah yang pernah ditipu menjelaskan;

“...surat kuasa tanda persetujuan tanah diserahkan dan kemudian dijanjikan akan diganti semula dengan tanah baru.."

Dalam pada itu, pemberian tanah melalui kaedah pemberimilik secara geran komunal juga telah menyebabkan konflik di antara masyarakat adat dengan kerajaan negeri. Ini kerana pemberimilikan pemilikan melalui geran komunal telah menyebabkan pemilik tanah kehilangan hakmilik mutlak terhadap tanah yang diwarisi mereka sejak sekian lama. Keadaan ini telah menimbulkan rasa tidak puas hati masyarakat setempat sehingga mendorong kepada isu pertikaian yang berpanjangan sehingga mengancam usaha-usaha pihak terbabit untuk membangunkan kawasan yang berkaitan. Oleh itu subtopik seterusnya memberi penekanan terhadap faktor yang mendorong pertikaian masyarakat adat terhadap tanah geran tanah komunal.

\section{Punca yang mendorong pertikaian pemberimilik tanah}

Pertikaian dalam pemberimilikan tanah seringkali berkait dengan rasa tidak puas hati, kebimbangan dan keraguan pemilik tanah terhadap ejen pembangunan. Sehubungan itu, pendekatan institusi telah mengklasifikasikan sebab pertikaian yang berlaku dalam proses pembangunan tanah kepada dua iaitu kekangan peraturan formal dan kekangan peraturan informal.

Faktor halangan peraturan formal pada dasarnya menyentuh halangan dalam bentuk akta, dasar dan sebagainya. Bagi North (20013), peruntukan dalam akta tanah boleh menjadi sebab terhadap pertikaian masyarakat. Sebagai contoh bantahan masyarakat adat di kawasan kajian jelas apabila ramai dalam kalangan mereka menyatakan wujudnya percanggahan antara geran komunal dengan akta tanah adat. Oleh yang demikian dalam kekangan peraturan formal ini, terdapat 3 peruntukan formal yang telah dikenalpasti membawa kepada bantahan masyarakat terhadap geran komunal antaranya akta tanah adat (NCR), peruntukan Geran Komunal dan sistem pengagihan tanah. Manakala bagi punca informal pula merangkumi ketelusan pihak berkuasa, adat dan budaya yang menjadi penyebab kepada pertikaian pemilikan tanah NCR.

\section{Kekangan peraturan formal yang menimbulkan bantahan terhadap penganugerahan pemberimilikan}

Analisis terhadap kekangan peraturan formal mendapati terdapat beberapa peruntukan formal yang telah menimbulkan bantahan pemilik tanah NCR terhadap penganugeran pemberimilik tanah melalui kaedah geran komunal. Bantahan tersebut diakibatkan oleh beberapa peruntukan undangundang seperti; 
a. Peruntukan dalam Akta Tanah Adat (NCR)

Peruntukan dalam Akta Tanah Adat (NCR) banyak menyentuh perihal pemilikan istimewa kepada anak Negeri Sabah. Tujuan pemilikan adalah bagi aktiviti sara diri dan mereka mengusahakan lebih daripada 3 tahun. Pemilikan tanah adat di Sabah juga banyak bersandarkan kepada pemilikan tidak bertulis seperti amalan pemilikan orang Asal. Antara amalan pemilikan yang membolehkan tanah adat diperoleh secara otomatik termasuklah; keperluan memenuhi syarat sebagai orang asal (peribumi Sabah), tanah adalah diperturunkan daripada generasi ke generasi dan ada bukti tanah diusahakan oleh mereka melebihi 3 tahun ( Seksyen 88 Ordinan Tanah Sabah).

Ramai dalam kalangan pemilik tanah beranggapan bahawa jika pemberimilik tanah secara geran komunal dilaksanakan sudah pasti hak istimewa dalam konteks pemilikan tanah adat akan hilang. Ini kerana dalam geran komunal anak negeri Bab 64 hanya menjadi benefisiari/peserta kepada geran komunal. Hal ini sudah pasti menimbulkan pertikaian antara pemilik tanah dengan kerajaan negeri. Hal ini jelas melalui rungutan daripada beberapa orang pemilik tanah antara;

“...jika kami ambil geran ini ...kami akan hilang hak atas tanah kami..apa lagi yang tinggal untuk anak cucu kami..."

Selain itu, pemakaian terhadap Akta Tanah Adat menyebabkan ramai pemilik tanah yang mempertikaikan keperluan kaedah pemberimilikan tanah secara geran komunal ini. Ramai pemilik tanah yang mengakui bahawa Geran Komunal akan menyebabkan perolehan tanah melalui Ordinan Tanah Bab 68 melalui pegangan adat mahupun kaum akan terjejas. Geran ini juga akan menyebabkan fungsi tanah adat dalam konteks geran mulai pudar secara perlahan-lahan. Kebimbangan bahawa masyarakat akan kehilangan identiti tanpa tanah adat menyebabkan beberapa orang pemimpin adat yang menyatakan bahawa;

“...kami tidak pernah setuju dengan pemberimilikan geran komunal..."

\section{b. Peruntukan dalam pemberimilikan geran komunal}

Bagi menangani isu pertindihan terhadap tuntutan tanah di Sabah, kerajaan negeri telah mencadangkan pemberimilikan tanah secara geran komunal. Melalui geran komunal, pemilik dijamin hak pemilikannya. Dalam hal ini pemilik tanah akan diberi dua pilihan sama ada mahu mengurus secara tradisional atau melalui wakil. Bagi mereka yang memilih pengurusan secara adat, hak mengurus diberikan secara total kepada mereka manakala secara wakil pula melibatkan pemberian tanah kepada individu untuk diusahakan mengikut jangkamasa yang dipersetujui. Walau bagaimanapun geran komunal tidak dapat menarik perhatian pemilik tanah dan dianggap merugikan apabila hanya anak negeri di bawah Bab 64 yang menjadi benefisiari kepada Geran Komunal.

Walaupun objektif geran ini jelas dalam konteks menyelesaikan isu dalam pemberimilikan serta melindungi kepentingan pemilik tanah. Namun majoriti berpendapat penganugerahan hak tanah secara komunal juga tidak akan dapat melindungi hak mereka terhadap tanah. Ini kerana melalui geran komunal mereka hanya berperanan sebagai peserta dan hak mereka terhadap tanah juga akan terhakis. Kebimbangan bahawa mereka akan kehilangan terhadap tanah melalui geran komunal ini menyebabkan pertikaian pemilikan tanah tidak dapat diselesaikan. 


\section{c. Peruntukan dalam Akta Pemilikan Tanah perkara 161 a}

Peruntukan dalam pengurusan Geran Komunal didapati tidak selari dan bercanggah hak terhadap Harta dalam Perkara 13 Perlembagaan Persekutuan. Peruntukan dalam Perkara 13 ini berkait dengan halangan terhadap pengambilan tanpa pampasan serta Akta 161 A yang menyentuh pemilikan tanah terhadap anak Negeri Sabah dan Sarawak. Akta 161 ini didapati sangat bercanggah dengan kaedah pemberimilik tanah secara geran komunal yang telah dicadangkan oleh kerajaan negeri. Pemilikan tanah secara pemegang amanah (benefisiari) telah menyebabkan tuan tanah kehilangan hak mutlak terhadap tanah yang mereka miliki melalui kaedah Geran Komunal ini.

Hal ini jelas apabila pemilik tanah sendiri menjelaskan bahawa pemilik tanah akan kehilangan kuasa terhadap tanah mereka apabila geran komunal dilaksanakan. Ini berikutan dengan kandungan dalam geran komunal langsung tidak menyentuh dan mengambilkira konsep tanah NCR yang digunapakai sebelum ini. Sedangkan tanah NCR dalam peruntukkannya jelas memberikan keutamaan kepada pemilik tanah adat melalui kelebihannya sebagai anak Negeri. Keadaan ini sudah pasti bercanggah dengan konsep tanah adat yang sebelum ini menjamin hakmilik secara kekal oleh pemiliknya. sejak sekian lama. Keadaan menjadi semakin rumit apabila Geran Komunal juga menyarankan adanya penyerahan tanah kepada orang luar melalui konsep usahasama. Keadaan ini menambahkan lagi kebimbangan masyarakat adat tentang kedudukan tanah mereka. Rungutan daripada beberapa orang pemilik tanah menjelas kebimbangan mereka;

“...Ini tidak sesuai dengan undang-undang tanah kami...bila-bila sahaja kami akan hilang hak kami..."

Dapatan kajian juga menjelaskan bahawa Geran Komunal telah menggabungkan beberapa buah kampung Tanah Adat (NCR). Bagi masyarakat adat keadaan ini tidak seharusnya berlaku. Mereka bimbang pemilikan secara benefesiari akan menolak hak mereka terhadap tanah adat yang diwarisi sejak sekian lama. Hal ini sudah pasti didapati sangat bercanggah dengan peruntukan tanah adat yang sedia. Bagi Pejabat Tanah yang menguruskan geran tanah komunal ini pula menjelaskan bahawa yang tidak menyalahi peruntukan yang ada. Ini kerana pemberimilikan tanah kepada anak negeri Sabah masih tertakluk di bawah seksyen 9 (1) Ordinan Tanah Sabah. Bagi pihak kerajaan peruntukan dalam Geran komunal ini bertujuan mengelakkan berlakunya penjualan tanah adat. Namun bagi pemilik tanah adat tiada istilah penjualan tanah tetapi hanya melibatkan sewaan tanah dalam tempoh tertentu dan bagi mereka jika berlaku penjualan ianya hanya melibatkan ahli dalam suku kaum mereka sahaja.

\section{d. Pengagihan tanah dalam Ordinan Tanah Sabah.}

Pengagihan tanah di Sabah adalah tertakluk kepada Ordinan Tanah Sabah dibawah seksyen 5 dan 6. Bagi Seksyen 5 tentang pemilikan tanah oleh kerajaan negeri menjelaskan bahawa "The entire property in and control of State land or land reserved for a public purpose is and shall be vested solely in the Government"

Manakala bagi Seksyen 6 pula menjelaskan bahawa "notwithstanding anything to the contrary contained in this Ordinance or in any written law relating to limitation of suits in force in Sabah, no unlawful occupation of State land or land reserved for a public purpose or residential purpose or occupation under temporary licence for however long a period shall establish any right, title or interest in State land or land reserved for a public purpose or residential purpose or create any right to demand a title to such land from the Government". 
Secara dasarnya sistem pemberimilikan tanah yang diamalkan di Sabah adalah secara terbuka. Oleh demikian permohonan tanah boleh dilakukan pada kepada sesiapa yang memohon tanah berkenaan. Dalam keadaan ini tidak wujud halangan permohonan terhadap mana-mana tanah, selagi ianya sah tanah tersebut belum mempunyai geran kepada sipemunya. Keaadaan ini bersesuaian dengan kaedah pemberimilik tanah oleh kerajaan negeri yang asasnya berasaskan kepada beberapa pra syarat tertentu dan tertakluk kepada beberapa peruntukan seperti perkara seksyen 9 (1) Ordinan Tanah Sabah, Seksyen 76 bagi Geran Komunal, Seksyen 78 bagi rizab tanah simpan dan seksyen 13 hingga 16 dan Perkara 88.

Dapatan daripada agihan tanah di kawasan kajian menjelaskan bahawa pemilik tanah adat bersetuju dengan tatacara pengendalian tanah oleh kerajaan negeri. Mereka pada umumnya bersetuju dan memahami bahawa kelulusan permohonan mereka amat bergantung kepada kesediaan tanah yang ada. Namun mereka kecewa kerana tempoh kelulusan yang mengambil masa yang lama walaupun Sabah mempunyai lebih daripada satu kaedah pemberimilikan tanah. Walau bagaimanapun disebabkan tempoh kelulusan yang lama seringkali wujud pencerobahan ke atas tanah-tanah kosong milik kerajaan. Walau bagaimanapun jika dilihat dalam konteks adat ianya dibenarkan dengan pembuktian ada tanaman dan penempatan yang telah dibuat oleh masyarakat. Namun hal ini bercanggah pula dengan peruntukan kerajaan. Situasi sebegini telah mewujudkan pertikaian apabila peruntukan adat membenarkan tetapi dalam peruntukan formal yang sedia ada iana menyalahi undang-undang. Oleh yang demikian ramai dalam kalangan pemilik tanah cuba untuk mendapatkan geran tanah tetapi timbul masalah permohonan geran memerlukan kos yang banyak bermula daripada kerja-kerja pengukuran tanah, pembayaran premium dan sebagainya. Pandangan daripada pemilik tanah menjelaskan bahawa;

“...bila semua orang boleh dapat tanah..inilah masalahnya..maka makin banyaklah permohonan tanah tidak selesai..tambah macam kami yang miskin ni ..."

Rumusannya walaupun terdapat banyak kekangan dalam peruntukan undang-undang formal namun terdapat juga halangan dalam peruntukan peraturan informal yang boleh mencetuskan pertikaian dalam pemilikan tanah. Antara peruntukan informal yang mendorong berlaku pertikaian dalam pemilikan tanah adalah adat dan budaya.

\section{Pertikaian yang berpunca daripada peruntukan dalam peraturan informal}

North (2003) dan Azima (2013) menjelaskan peruntukan informal melibatkan peruntukan bukan undang-undang yang mempengaruhi cara hidup masyarakat. Oleh itu terdapat beberapa peruntukan informal yang boleh menyebabkan pertikaian antara pemilik tanah dengan pihak kerajaan negeri. Dapatan di lapangan menjelaskan wujud 3 peruntukan informal yang menyebabkan pertikaian berlaku antara berkait dengan ketelusan pihak berkuasa dalam memberikan maklumat tentang pelaksanaan geran komunal, peruntukan adat dan juga budaya

\section{Ketelusan pihak berkuasa}

Ketelusan pihak berkuasa dalam mengendalikan sumber kekayaan negara perlu dilakukan dengan sebaik-baiknya (Azwan Syah et al., 2015; Noor Ashikin et al., 2011). Integriti dalam kalangan pihak berkuasa sangat diperlukan agar sumber alam yang seperti tanah dapat diagihkan secara adil agar hak masyarakat terhadap tanah dipastikan. Keadaan ini boleh mengurangkan rungutan dan 
rasa tidak puas hati masyarakat terhadap polisi dan dasar yang telah dilaksanakan. Dalam konteks pemberimilikan tanah secara komunal ini pemahaman masyarakat terhadap polisi dan dasar pelaksanaan harus diberikan perhatian yang khusus, agar tidak timbul perasaan tidak puas terhadap tatacara pelaksanaan.

Analisis terhadap ketelusan pihak berkuasa mendapati mereka kurang bersetuju degan pandangan cara pihak berkuasa mendapatkan persetujuan daripada mereka. Ramai dalam kalangan responden berpendapat mereka tidak mempunyai pengetahuan yang jelas tentang geran komunal sehingga mereka menandatangani perjanjian untuk setuju terlibat dalam geran tersebut. Hal ini apabila terdapat rungutan daripada pemilik tanah yang menyatakan;

“...pada peringkat awal mereka diberitahu bahawa mereka akan diberikan geran tanah dan mereka dikehendaki mendaftarkan nama mereka..."

Situasi ini menyebabkan mereka rasa tertipu kerana tidak diberikan penerangan jelas bagaimana geran milikan tersebut beroperasi. Dalam pada itu pemilik tanah adat juga tidak bersetuju kiranya geran ini dapat menggambarkan usaha pihak kerajaan untuk mengatasi isu pemilikan tanah adat. Bagi pemilik tanah adat, pemberimilikan tanah secara geran komunal telah menyebabkan isu yang berkait pemilikan tanah menjadi semakin rumit. Walaupun Pejabat Tanah menyatakan kaedah ini adalah yang terbaik bagi mengatasi masalah pemilikan tanah namun bagi pemilik tanah adalah sebaliknya. Ramai dalam kalangan pemilik tanah yang menjadi marah apabila ramai dalam kalangan mereka tidak dianugerahkan dengan tanah yang mereka mohon. Malah ada juga tanah yang bertukar pemilik sebaik sahaja geran ini diluluskan. Hal ini jelas mengambarkan perasaan tidak puas hati masyarakat adat dengan pihak kerajaan negeri. Situasi ini akhirnya menyebabkan wujudnya pertikaian yang berlanjutan antara kedua-duanya.

\section{Peruntukan adat masyarakat setempat}

Dalam konteks pemilikan tanah adat, masyarakat mempunyai peruntukan tersendiri dalam menentukan sempadan dan pemilikan (Azman Syah et al., 2015). Maklumat informal masyarakat adat ini seringkali bercanggah dengan maklumat yang diperoleh daripada Pejabat Tanah. Persempadanan dan pemilikan tanah adat difahami melalui proses lisan. Seringkali pemilik tanah menandai sempadan pemilikan tanah mereka dengan menggunakan bahan fizikal sekeliling yang mudah ditemui seperti pokok dan sebagainya. Tujuannya agar mereka mudah mengingati pesempadanan yang telah ditandai walaupun setelah sekian lama. Tambahan pula bahan yang dipilih untuk penandaan fizikal persempadanan tanah pada kebiasaanya senang diperoleh dan tahan lasak.

Analisis terhadap peruntukan adat ini menjelaskan bahawa apabila geran komunal digunakan sebagai kaedah dalam pemberimilikan tanah, maka adat dan kepercayaan nenek moyang mereka terhadap tanah adat menjadi terhakis. Dalam pada itu, geran komunal ini juga dikatakan menghapuskan hak masyarakat terhadap tanah yang diterokai oleh nenek moyang mereka. Walaupun geran komunal bertujuan untuk melindungi kepentingan penduduk terhadap tanah yang mereka miliki namun ramai dalam kalangan pemilik beranggapan sebaliknya. Bagi mereka geran komunal telah menyebabkan mereka kehilangan hak terhadap tanah. Walaupun isu awal pengenalan pemberimilikan tanah melalui kaedah ini bertujuan untuk mengurangkan pertindihan permohonan tanah, namun usaha ini tidak mendapat sambutan yang baik. Apabila isu perkongsian pemilikan tanah dengan orang luar menimbulkan rasa bimbang dalam kalangan pemilik. 
Keadaan ini lama-kelamaan akan mengikis tatacara perolehan tanah yang diwarisi mereka sejak sekian lama. Hal ini sudah pasti memberi kesan terhadap amanah yang telah diberikan oleh orang tua mereka terhadap tanah yang mereka warisi. Tambahan, bagi pemilik tanah adat, mereka beranggapan bahawa tanah adat mempunyai nilai-nilai yang berkait dengan kelangsungan warisan budaya dalam komuniti Bajau. Bagi komuniti Bajau pemilikan tanah dalam kalangan mereka membolehkan komuniti mereka terus berkembang. Tambahan pula tanah yang dimililki secara warisan ini memberikan mereka ruang untuk membina penempatan dan bercucuk tanam demi kelangsungan hidup dari satu generasi kepada generasi berikutnya. Oleh itu, tanah umpama kehidupan kepada mereka, tanpa tanah amat sukar untuk mereka meneruskan kehidupan.

\section{Peruntukan budaya masyarakat adat}

Tanah adalah sesuatu yang sangat penting dalam komuniti Bidayuh. Tanah dianggap sebagai simbol identiti budaya mereka yang diwarisi secara turun temurun. Pemilikan dan pengekalan tanah dari satu keturunan kepada keturunan berikutnya merupakan suatu kebanggaan terhadap suku kaum Bajau di Semporna. Ini kerana tanah adat sesuatu yang diwarisi dalam konteks identiti dan budaya mereka. Ini bermakna tanpa tanah komuniti Bajau akan kehilangan identiti dan budaya mereka.

Selain itu, bagi suku Bajau tanah dilihat sebagai suatu lambang yang mempunyai nilai kekeluargaan yang sangat tinggi. Tanah adalah hadiah yang sangat besar nilainya kepada generasi yang mewarisinya. Maka tidak hairan jika wujudnya penentangan terhadap geran komunal, kerana geran komunal tidak memberikan penekanan terhadap budaya pemilikan secara kolektif. Sebaliknya pemilik geran komunal dianggap sebagai peserta dalam geran komunal. Keadaan ini lama-kelamaan akan menghakis budaya masyarakat adat. Peruntukan dalam geran komunal yang diperkenalkan oleh Pejabat Tanah juga telah merumitkan aspek yang berkait dengan pemilikan tanah mereka. Jika dulu permohonan tanah hanya melibatkan persetujuan Dato Panglima namun kini keadaan menjadi semakin rumit apabila perincian perlu diberikan kepada Pejabat Tanah sebelum kelulusan diberikan. Keadaan ini secara perlahan-lahan boleh menghilangkan hakmilik masyarakat terhadap tanah adat. Dalam pada itu perubahan dalam nilai dan kepenggunaan tanah adat juga akan mengubah budaya masyarakat terhadap tanah.

\section{Kesimpulan}

Rumusannya pertikaian masyarakat adat terhadap tanah melibatkan dua sebab yang utama iaitu formal dan informal. Pertikaian masyarakat adat dengan pihak agensi ini sebenarnya berpunca rasa tidak puas hati dan perasaan ragu-ragu pemilik tanah terhadap peruntukan formal seperti akta dan undang-undang tanah. Analisis peruntukan formal mendapati peruntukan dalam Geran Komunal tidak memberikan sebarang manfaat dalam konteks sosial budaya masyarakat. Malah mereka mendapati pemberimilikan tanah melalui kaedah ini akan menyebabkan berlakunya perlucutan pemilikan tanah. Begitu juga dengan peruntukan informal secara jelas mengambarkan kebimbangan masyarakat terhadap kehilangan kuasa autoriti mereka terhadap tanah. Keadaan ini boleh menyebabkan wujudnya perubahan dalam institusi masyarakat adat dan akhirnya mengubah budaya masyarakat adat. Oleh kerana terdapat banyaknya bantahan dalam kalangan masyarakat adat berhubung dengan kaedah pemberimilikan tanah adat ini melalui geran komunal, maka pihak 
kerajaan telah bertindak menggantikan dengan kaedah pemilikan individu yang lebih adil pada masyarakat adat.

\section{Penghargaan}

Penyelidikan ini dibiayai oleh Geran Galakan Penyelidikan UKM (GGP-2017-073)

\section{RUJUKAN}

Azima Abdul Manaf, \& Er Ah Choy. (2015). Isu pemilikan tanah dan implikasinya terhadap produktiviti pekebun kecil: Kajian kes pekebun kecil di Lahad Datu, Sabah. GeografiaMalaysian Journal of Society and Space, 11(9), 112-124.

Azima Abdul Manaf \& Ismail Omar. (2013). Tanah pertanian terbiar: Ekonomi institusi. Bangi: UKM Press:

Azima A. M., Mohd Yusoff Husain, Suhana Saad, \& Nurul Kamariah. (2012). Aplikasi pendekatan institusi ekonomi ke atas tanah pertanian terbiar di pulau-pulau sekitar Mersing, Johor. Geografia-Malaysian Journal of Society and Space, 8(5), 14-25.

Azwan Syah Idris, Nordin Hussin \& Ishak Yusof. (2015). Pelaksanaan customary tenure enactment (CTE) zaman kolonial dan kesannya ke atas pentadbiran tanah adat di Negeri Sembilan (1921-1940). Kajian Malaysia, 33(1), 67-92.

Bernama. (2018). Sabah beri geran individu, mansuhkan geran komunal.

Borneo Today. (2018). Geran Komunal dimansuhkan; penerima diberikan tanah Native Tittle.

D’Arcy, E., \& Keogh, G. (2002). The market context of property development activity. Dlm Guy S and Henneberry J. (pynt). Development and Developers: Perspective on Property. United Kingdom: Blackwell Science.

Ah Choy Er, Habibah Ahmad and Azima Abdul Manaf. 2021. Comparative Cost Benefit Analysis of Coventional Farming ang Agroecological Farming for Paddy Cultivation in Bachok, Kelantan. International Journal of Environmental Sciences and Development, 12(6), 181 187.

Hodgson, G. M. (2000). What is the essence of Institutional Economics. Journal of Economic Issues, 34, 166-92.

Hazakis, K. 2014. The rationale of special economic zones (SEZs): An Institutional approach. Regional Science Policy \& Practice, 6(1), 85-101.

Ganta, B. G. (2019). Access to rural land right in the post-1991 Ethiopia: Unconstitutional policy shift. Journal of Land Rural Studies, 7(1), 1-22.

International Organization for Migration (IOM) \& the World Bank. (2013). Land Disputes In Conflict Affected Areas Of Mindanao: Report Of The Joint World Bank - International Organization For Migration Scoping Mission. 1-39.

Keogh, G., \& D’Arcy, E. (1998). Property market efficiency: An institiutional perspective. Discussion Paper 98-02, Aberden. Papers in Land Economy.

Mair, D. \& Miller, G. (1992). A modern guide to economic thought: An introduction to comparative schools of thought of economic. London: Edward Elgar.

Mohamad Nawab, M. O., \& Rajaratnam, S. (2017). A transitioning Sabah in charging Malaysia. Kajian Malaysia, 35(1), 23-40. 
Hassan Mat Noor. 2002. Pendidikan dan masa depan komuniti orang Asli dalam masyarakat dan perubahan. Bangi: UKM Press.

Hebo, M. (2005). Land Disputes Settlement In A Plural 'Institutional' Setting: The Case Of Arsii Oromo Of Kokossa District, Southern Ethiopia. African Study Monographs, 29, 125-135.

Lee Jing. (2017). Exploring the narrive of heritage trough the eyes of Law. Kajian Malaysia, 35(1), 185-207.

North, D. C. (2005). Understanding Economic Change. Cambridge: Cambridge University Press.

North, D. C. (1996). Institution, institutional change and economic performance. Cambridge: Cambridge University Press.

Nasution Naejel. (2011). Kaum Murut tolak Geran Komunal. Misi Sabah May 27.

Nasser Hamid. (2009). Sabah Land Ordinance. Gavel Publication. Kuala Lumpur.

Marcus, B. L. (2006). The role of planning in achieving indigenous land justice and community goals. Land Use Policy, 23(4), 385-394.

Paaga, D. T. (2013). Customary land tenure and its implications for land disputes in Ghana: Cases from Wa, Wechu and Lambussie. International Journal of Humanities and Sosial Science, 3(18), 263-270.

Shahidul Islam, Golam Moula, \& Mominul Islam. (2015). Land rights, land disputes and land administration in Bangladesh - A critical study. Beijing Law Review, 6, 193-198.

Sabah Land Ordinance (Cap 68) with relevant subsidiary Legislation. (2016). 2nd Edition. Lexis Nexis.

Rooshida Merican Abdul Rahim Merican, Jady @Zaidi Hashim, Wan Syazana Akmal Wan Roslan \& Hanani Azren Husin. (2016). An introduction to Sabah Native Land Law. UKM Press: Bangi

Searle, R. J. (2005). What is an Institution? Journal of Institutional Economics, 1(1), 1-22.

United Nations. (2012). Land and Conflict. New York, US: UN Interagency Framework Team for Preventive Action. 